\title{
Data integration for rapid flood mapping and impact assessment
}

\author{
Kai Schröter ${ }^{1}$, Stefan Lüdtke ${ }^{1}$, Daniel Eggert ${ }^{2}$, Heidi Kreibich ${ }^{1}$, Bruno Merz ${ }^{1}$ \\ ${ }^{1}$ German Research Centre for Geoscience GFZ, Section Hydrology, Potsdam, Germany \\ ${ }^{2}$ German Research Centre for Geoscience GFZ, Section Geoinformatics, Potsdam, Germany
}

\begin{abstract}
Efficient flood disaster response and recovery need rapid flood mapping and impact assessments. Increasing amounts of data are available in near real-time from a growing diversity of sensors and data sources. Therefore we need to improve our capabilities of extracting and integrating knowledge from heterogeneous data sources. Using the June flood 2013 in Dresden as a use case, this study investigates whether the combination of multiple data sources provides more reliable and more accurate inundation depths maps for rapid flood impact assessments. In this example, we use remote sensing-based flood masks, water level observation and inundation depth-estimates extracted from photos shared in social media streams for inundation mapping. We assess the reliability and accuracy of the inundation maps and compare them with a combined multi-source inundation map as well as an official reference map. The results indicate that the combination of different data sources helps to close gaps in individual data sources. Further, it has a compensatory effect, which results in more reliable and more accurate inundation maps.
\end{abstract}

\section{INTRODUCTION}

With globally increasing flood losses during the last decades and with an expected further rise of flood impacts in the future due to anthropogenic climate change and increasing exposure, effective emergency response capabilities are a pressing issue on the agenda for global disaster risk reduction (UNISDR, 2015). Knowing the inundation situation and estimating impacts during or shortly after a flood is crucial for decision making in emergency response and recovery (Merz et al. 2020).

Flooding is a dynamic process with pronounced spatial and temporal variability. Moreover, changes in the flood system, for instance, levee breaches or taking emergency measures, may alter flow processes and cause unanticipated deviations from ex-ante contingency plans.

As floods may impact human activities and assets in manifold ways (Merz et al. 2010), for emergency management it is important to know which areas are flooded when and with which intensity. In contrast, flood impact assessment is more interested to know the maximum flooding extent as well as maximum inundation depths that occurred during the flood.

Increasing amounts of data are available in Near-RealTime from a growing diversity of sensors and data sources. This spans online reporting river gauges, flood predictions using fast numerical simulation models, unsupervised remote-sensing-based flood detection (e.g. Martinis et al. 2015) as well as traffic camera images (e.g. Schnebele et al., 2014) and or volunteered geographic information acquired from social media (Fohringer et al., 2015; Brouwer et al., 2017). A couple of studies demonstrate the

${ }^{a}$ Corresponding author: kai.schroeter@gfz-potsdam.de DOI 10.3311/FLOODRisk2020.3.8 usefulness of these data sources to derive flood masks (wet/dry classification) and, at times, inundation depth maps.

Each data source and associated processing chains have their inherent intricacies and challenges; hence they offer flooding information of varying quality and reliability. These data sources are usually scattered and derived data sets often do not cover the same area with coherent details in space and time and are not available at the same time. We start from the assumption that improvements in near real-time flood mapping and rapid impact assessment depend on our capabilities of extracting and integrating knowledge from these fast-growing heterogeneous data. On that account, our work builds on the hypothesis that the combination of complementary and or redundant data from multiple sources provides more reliable and more accurate inundation depths maps for rapid flood impact assessments.

We test this hypothesis using the June flood 2013 in Dresden (Germany) as an example. For the inundation mapping of this flood, we use a satellite-based flood mask, geo-located photos which show inundations and are shared via social media, and water level observations as instances for heterogeneous data from multiple sources. Terrestrial surveys and aerial images of flooded areas are available as independent reference data to evaluate the reliability and accuracy of inundation maps based on individual data sources and a combined product.

\section{DATA AND METHODS}




\subsection{June flood 2013 in Dresden}

In June 2013 widespread severe flooding hit Central Europe causing economic damage of about EUR 8.1 billion alone in Germany where particularly the Elbe catchment has been affected (Schröter et al., 2015; Thieken et al., 2016). The Elbe traverses the city of Dresden and in June 2013 it has flooded several city districts. On 6 June 2013, the peak water level at the gauge Dresden reached $876 \mathrm{~cm}$ above gauge datum which corresponds to an absolute height of 111.3 masl. A water level of $850 \mathrm{~cm}$ which corresponds to a 20 years flood leads to flooding in the city districts Laubegast and Kleinschachwitz upstream and Pieschen Süd downstream of the city centre.

\subsection{Data sources for inundation mapping}

Data sources for inundation mapping include a satellite-based remote sensing flood mask, water level recordings at the online reporting gauge in the city centre of Dresden and inundation depth estimates extracted from geo-located photos that have been filtered from social media data streams. A detailed post-event inundation depth map based on terrestrial survey data and aerial images is available from the German Federal Institute of Hydrology (BfG) as a reference map for evaluating the quality of the produced inundation maps.

Each data source has a dedicated data processing workflow to derive inundation depth maps by combining information about water levels, inundated locations and areas with topography information from digital elevation models (DEM). In this study, we utilize the $10 \mathrm{~m}$ and $5 \mathrm{~m}$ resolution DEMs available from the Federal Agency for Cartography and Geodesy in Germany (C) GeoBasis-DE / BKG (2010). All following data sets have been prepared to match the spatial resolution of these DEMs.

\section{Remote sensing-based flood mask}

A flood mask of the June 2013 flood in Dresden is available from Perils AG (www.perils.org) which is based on Pleiades HR1A multispectral image taken on 5 June 2013 with a horizontal resolution of $50 \mathrm{~cm}$. In this product, a SPOT 5 multispectral image from 21 August 2011 has been used as a reference to classify flooded areas and permanent water surfaces. The water body of the Elbe River is included in the flood mask. This land/water boundary is input to the floodwater depth estimation algorithm proposed by Cohen et al. (2017) which uses a focal statistic approach. In brief, starting from the elevation level of the points on the land/water boundary, this algorithm extends the flooded area to adjacent pixels in an iteration loop. The inundated area and inundation depth are determined as the difference between water level and DEM elevation.

\section{Water level observations}

The water level observation for the flood peak at the gauge Dresden is linearly extrapolated along the reach of the Elbe River in Dresden and intersected with a DEM (Apel et al., 2009). The slope of the water level along the reach is approximated by differences of elevations extracted for equidistant points along the centreline of the watercourse. The resulting inclined water surface level is intersected with DEM elevations, such that the areas below the water surface are indicated as flooded and the inundation depth is the water surface level minus the terrain elevation.

\section{Social media photos}

Processing of flooding information extracted from social media photos uses a very similar approach to water level extrapolation. In a nutshell, inundation depths at the location shown in a photo are estimated from the context information of the photos. For instance, a park bench in floodwaters may indicate a water depth of approximately $0.5 \mathrm{~m}$. These point estimates of inundation depth are added to the terrain elevation given by the DEM in this location. Using these sample points the spatial continuous water surface is approximated using a 2-dimensional spline method. Again, the difference of the water surface and terrain elevations indicates flooded areas and gives the inundation depth. Flood photos have been filtered from Twitter and Flickr using the PostDistiller tool of Fohringer et al., (2015). This tool filters images using keywords related to flooding and associated impacts as well as temporal and spatial constraints. Hence, the availability of geo-location information attached to the photos is needed to match to the region of interest. Also, the timing of the post is preferably close to the occurrence of the flood peak. For the Dresden example a number of 84 geo-located posts with photos attached are available within the target time and area. As a result of plausibility checks and expert image evaluation a total number of 5 inundation depth estimates are derived for subsequent flood inundation mapping.

\section{Reference inundation map}

The post-event data set of BfG is based on terrestrial surveys and aerial image analysis and provides a spatial polygon which delineates the flooded areas during the June 2013 flood along the Elbe. It also includes the elevation nodes at the land/water boundary. These data have been spatially interpolated using a Kriging approach to derive a reference inundation depth map for Dresden.

\subsection{Data integration and combination}

The inundation depth maps derived from the multiple data sources described above are assumed to provide alternative representations of the same flooding situation. As a preliminary step to investigate whether the combination of these data sources increases the reliability 
and accuracy of inundation depth maps, we apply a straightforward averaging approach.

First, all data sources are harmonized in terms of the coordinate reference system, spatial resolution, length units, and region covered. Next, the spatial overlay of the data sources gives an agreement level regarding flooded and non-flooded pixels. The number of data sources which indicate an individual pixel as flooded are summed-up, such that, for instance, a pixel which is indicated as flooded by two of the three data sources will have a value of 2. This heuristic represents a trade-off between increasing confidence, i.e. several independent observations indicate flooding, and controlling a bias towards large flood extents, i.e. unifying all flooded pixels. Using the resulting agreement map, we constrain the combined inundation map to areas where at least two data sources indicate flooding. Finally, we calculate the average inundation depth from the contributing data sources in each pixel. Using the resulting agreement map, we constrain the combined inundation map to areas where at least two data sources indicate flooding. Finally, for these areas, we calculate the average inundation depth from the contributing data sources in each pixel.

\subsection{Evaluation criteria}

The inundation depth maps are evaluated in terms of reliability with regard to the performance to recognize flooded and non-flooded areas, and in terms of accuracy regarding inundation depth values. For the categorical prediction of flooded and non-flooded areas we use the true skill statistic (TSS). TSS uses all elements of the contingency table and quantifies how well the prediction of flooded areas separates the flooded from the nonflooded areas. It ranges from -1 to 1 ; with 1 as the perfect score and 0 indicating no skill.

The accuracy of inundation depths values is compared using the root mean square error and the mean bias error from the comparison of predicted inundation depths and the reference data. Further we report the maximum error obtained. Accuracy metrics are only evaluated in the area where the reference inundation map shows flooding.

\section{Results}

The extent of the flooded areas identified for the June flood 2013 in Dresden varies considerably for the different data sources (Figure 1). The reference data from BfG shows that mainly the floodplain areas along the Elbe River have been flooded in June 2013. Besides, areas in the city centre as well as in the district of Laubegast upstream of Dresden have been affected (Figure 1 panel e).

The remote sensing-based flood map reasonably reflects the flood extent but the inundated areas are somewhat patchy with a large blind spot in the centre of the region of interest (Figure 1 panel a).
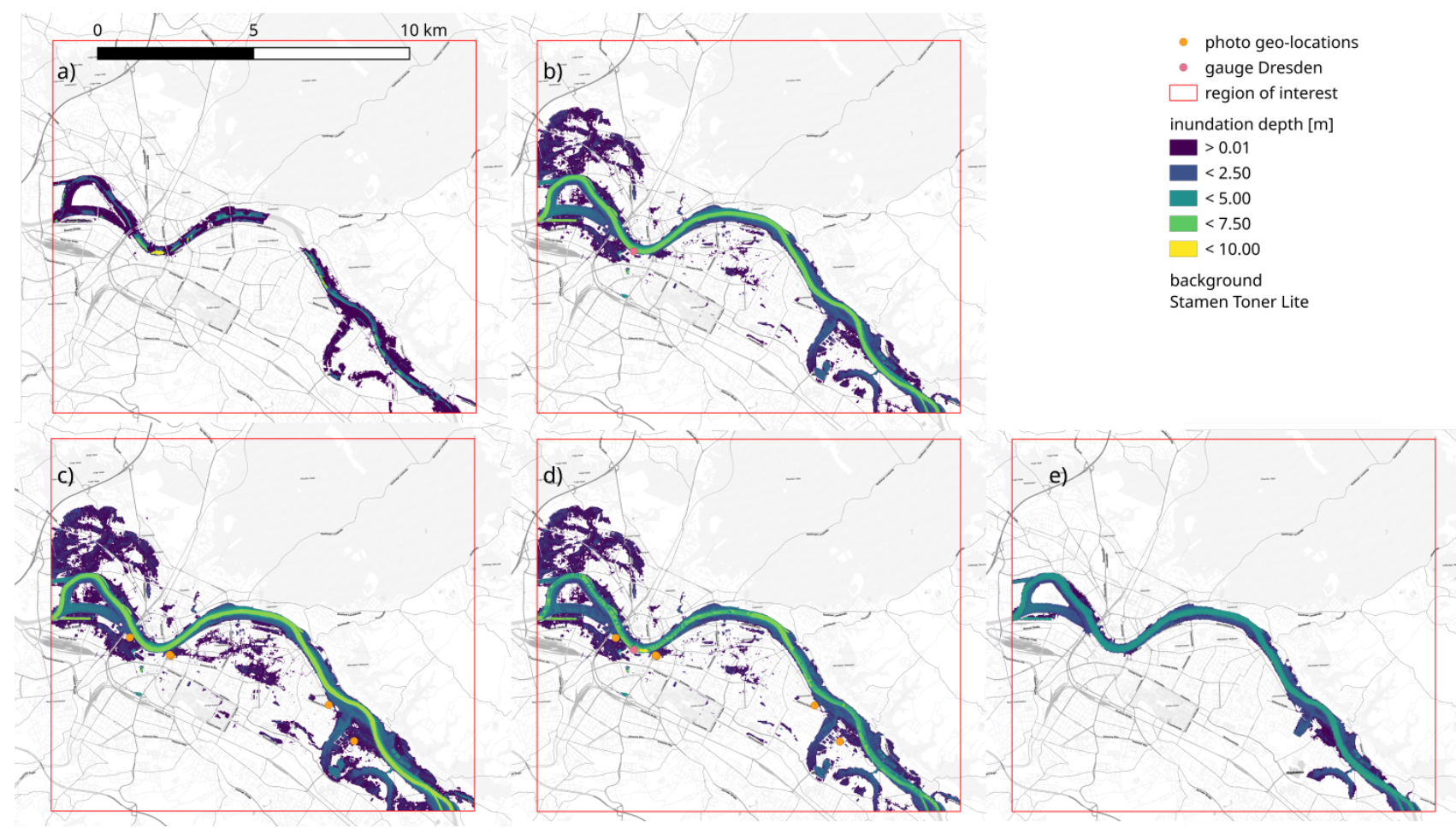

Figure 1. Inundation depth maps from multiple data sources: a) remote sensing-based, b) water level extrapolation from observations at gauge Dresden (pink dot), c) social media photos (geo-locations of photos marked with orange dots), d) multi-source combined map, e) reference inundation map; all maps are based on 5 m DEM (C) GeoBasis-DE / BKG (2010). 
The water level-based flood map clearly shows more extended areas affected by flooding than the reference data suggests. Particularly the areas downstream of the gauge Dresden (district Pieschen Süd) and upstream (district Laubegast) plus some scattered areas in the city centre are flooded (Figure 1 panel b).

The flood map based on social-media photos is quite similar to the water level-based product but shows even larger flooded areas (Figure 1 panel c).

Finally, the map combined from the multiple data sources resembles closely the water level-based inundation map (Figure 1 panel d).

The water level-based map and the multi-source combination maps achieve similar skill scores, which are slightly better than the skill score of the map based on social-media photos and notably higher than the skill score of the remote sensing-based map (Table 1). Overall, the multi-source combination map achieves best skill and accuracy metrics when using the 5m DEM data. These results for the skill score are consistent for using 5 and 10 $\mathrm{m}$ DEM resolution data. However, the inundation maps are more accurate and less biased when using the 10m DEM.

\begin{tabular}{|c|c|c|c|c|}
\hline $\begin{array}{l}\text { Data } \\
\text { source }\end{array}$ & Skill & MAX & RMSE & MBE \\
\hline \multicolumn{5}{|c|}{$5 \mathrm{~m} \mathrm{DEM}$} \\
\hline $\begin{array}{l}\text { Remote } \\
\text { Sensing }\end{array}$ & 0.452 & 15.288 & 0.705 & -0.128 \\
\hline Water level & 0.943 & 11.779 & 0.342 & 0.047 \\
\hline $\begin{array}{l}\text { Social media } \\
\text { photos }\end{array}$ & 0.924 & 11.854 & 0.411 & 0.071 \\
\hline $\begin{array}{l}\text { Multi-source } \\
\text { combination }\end{array}$ & 0.943 & 11.817 & 0.289 & 0.030 \\
\hline \multicolumn{5}{|c|}{ 10m DEM } \\
\hline $\begin{array}{l}\text { Remote } \\
\text { Sensing }\end{array}$ & 0.374 & 11.991 & 0.776 & -0.149 \\
\hline Water level & 0.938 & 7.830 & 0.131 & 0.004 \\
\hline $\begin{array}{l}\text { Social media } \\
\text { photos }\end{array}$ & 0.931 & 8.283 & 0.192 & 0.033 \\
\hline $\begin{array}{l}\text { Multi-source } \\
\text { combination }\end{array}$ & 0.938 & 5.950 & 0.190 & -0.002 \\
\hline
\end{tabular}

Table 1. Performance metrics for inundation depth maps using remote sensing, water level observations, social media photos and multi-source combination for 5 and $10 \mathrm{~m}$ DEM resolution. Best performance values are marked bold.

\section{Discussion and conclusions}

In this study, we conduct a preliminary analysis for using heterogeneous data from multiple-sources for rapid inundation mapping. The inundation mapping approaches which are used to translate the remote sensing-based flood mask, water level observations and social media photos into inundation maps represent just one of many options. Adjustments and possible improvements to these algorithms will most likely enhance the performance. For

\footnotetext{
${ }^{a}$ Corresponding author: kai.schroeter@gfz-potsdam.de DOI 10.3311/FLOODRisk2020.3.8
}

instance, the analysis of flood plain flow paths and the assessment of hydraulic connectivity to sources of flooding including information about e.g. flood protection schemes could help to avoid ponding and to eliminate suspiciously scattered inundation areas. Also, the combination of multi-source inundation maps can be done in a more sophisticated way than conducted here. In this respect, statistical, machine-learning or Bayesian approaches would allow capturing and quantifying the uncertainty associated with different input data.

Social media photos are associated with considerable uncertainty regarding the inundation depth estimated from the image context, the timing when the picture was taken and the geo-location information provided. As floods are dynamic, the information derived from the photo must be placed in the temporal course of the flood event. This has to take into consideration that the photo may not show the situation at the time of the flood peak. Spatial offsets of the photo location may bias the extracted terrain elevation, and thus over- or underestimate the water surface elevation.

Likewise, elevation nodes extracted from DEMs for the land/water boundary largely impact the estimation of the water surface elevation and derived inundation map. In our example application, this effect can be observed for the remote sensing-based inundation map in the vicinity of the gauge Dresden. In this area, very high elevation values are extracted from the DEM and result in excessive inundation depths (Figure 1, panel a). Accordingly, the spatial resolution and the vertical accuracy of the DEM are important. Still, a thorough review and careful clean-up and preparation of the data input to the inundation mapping algorithms are crucial.

While there is room for improvement, both regarding the inundation mapping algorithms and the combination of data sources, the results of our preliminary analysis offer support for our initial hypothesis that the combination of multi-source data increases reliability and accuracy of inundation maps. Our example application illustrates that the combination of different data sources helps to close gaps in individual data sources (e.g.in the remote sensingbased inundation map) and also have a compensatory effect.

In future research, we will address more sophisticated methods to combine multiple data sources. Further, we will investigate additional data sources, for instance, simulation models, as well as combinations of multiresolution data.

\section{Acknowledgements}

This work has been carried out with support from the Digital Earth Project (https://www.digitalearthhgf.de/home).

\section{References}

1. Apel, H., Aronica, G.T., Kreibich, H., Thieken, A.H. (2009). Flood risk analyses - how detailed do we need to be? Nat Hazards 49, 79-98. https://doi.org/10.1007/s11069-008-9277-8

2. Brouwer, T., Eilander, D., van Loenen, A., Booij, M.J., Wijnberg, K.M., Verkade, J.S., Wagemaker, J. 
(2017). Probabilistic flood extent estimates from social media flood observations. Nat. Hazards Earth Syst. Sci. 17, 735-747. https://doi.org/10.5194/nhess17-735-2017

3. Cohen, S., Brakenridge, G.R., Kettner, A., Bates, B., Nelson, J., McDonald, R., Huang, Y.-F., Munasinghe, D., Zhang, J. (2018). Estimating Floodwater Depths from Flood Inundation Maps and Topography. JAWRA Journal of the American Water Resources Association

54 ,

847-858. https://doi.org/10.1111/1752-1688.12609

4. Fohringer, J., Dransch, D., Kreibich, H., Schröter, K. (2015). Social media as an information source for rapid flood inundation mapping. Nat. Hazards Earth Syst. $\quad$ Sci. $\quad \mathbf{1 5}, \quad$ 2725-2738. https://doi.org/10.5194/nhess-15-2725-2015

5. Frey, D. (2012). Damage Assessment System of Linear Infrastructure Objects during Flooding using Probabilistic Graphical Models. Technische Universität München.

6. Martinis, S., Kersten, J., Twele, A. (2015). A fully automated TerraSAR-X based flood service. ISPRS Journal of Photogrammetry and Remote Sensing 104, 203-212.

https://doi.org/10.1016/j.isprsjprs.2014.07.014

7. Merz, B., Kreibich, H., Schwarze, R., Thieken, A.H. (2010). Review article "Assessment of economic flood damage." Nat. Hazards Earth Syst. Sci. 10, 1697-1724. https://doi.org/10.5194/nhess-10-16972010

8. Merz, B., Kuhlicke, C., Kunz, M., Pittore, M., Babeyko, A., Bresch, D.N., Domeisen, D.I.V., Feser, F., Koszalka, I., Kreibich, H., Pantillon, F., Parolai, S., Pinto, J.G., Punge, H.J., Rivalta, E., Schröter, K., Strehlow, K., Weisse, R., Wurpts, A. (2020). Impact Forecasting to Support Emergency Management of Natural Hazards. Rev. Geophys. 58. https://doi.org/10.1029/2020RG000704

9. Schnebele, E., Cervone, G., Kumar, S., Waters, N. (2014). Real Time Estimation of the Calgary Floods Using Limited Remote Sensing Data. Water 6, 381398. https://doi.org/10.3390/w6020381

10. Schröter, K., Kunz, M., Elmer, F., Mühr, B., Merz, B. (2015). What made the June 2013 flood in Germany an exceptional event? A hydro-meteorological evaluation. Hydrol. Earth Syst. Sci. 19, 309-327. https://doi.org/10.5194/hess-19-309-2015

11. Thieken, A.H., Bessel, T., Kienzler, S., Kreibich, H., Müller, M., Pisi, S., Schröter, K. (2016). The flood of June 2013 in Germany: how much do we know about its impacts? Nat. Hazards Earth Syst. Sci. 16, 1519-1540. https://doi.org/10.5194/nhess-16-15192016

12. UNISDR, 2015. Sendai Framework for Disaster Risk Reduction 2015-2030. United Nations International Strategy for DisasterReduction. 